\title{
PUERTOS LOCALES Y BIENES DE CONSUMO: IMPORTACIÓN DE MERCANCÍAS FINAS EN SANTANDER, COLOMBIA, 1870-1900
}

\author{
LOCAL PORTS AND CONSUMER GOODS: \\ IMPORT OF FINE GOODS IN SANTANDER, \\ COLOMBIA, 1870-1900
}

\author{
Clara Inés Carreño Tarazona \\ Universidade Estadual Paulista, Assis, Brasil, clarainesct@gmail.com
}

\begin{abstract}
Resumen. Este artículo analiza la importación de bienes de consumo, el medio social y los puertos locales, así como elementos que formaron parte del circuito mercantil en Santander, Colombia, entre 1870 y 1900. En primer lugar se examina el movimiento comercial realizado entre los principales puertos extranjeros y los puertos locales colombianos. En segundo lugar se estudian las diversas formas de asociación, adoptadas por los principales importadores para incursionar en el comercio exterior. Finalmente, se indican los bienes y mercancías de lujo, introducidas por dichos importadores, y su incorporación en los diferentes grupos sociales. Las fuentes empleadas son los protocolos notariales, los registros de aduanas y de consulados, los fondos judiciales, las gacetas departamentales y los diarios oficiales.
\end{abstract}

Palabras clave: puertos; importación; casas comerciales; circuito mercantil.

Abstract: This article analyzes the import of consumer goods, social environment and the local ports, as elements that formed part of the merchant circuit in Santander, Colombia, between 1870 and 1900. First, examines the commercial movement between major foreign ports and the local Colombian ports. In second place are studied various forms of association adopted by the leading importers to venture into foreign trade. Finally, listed goods and luxury goods, introduced by these importers, and their incorporation into the various social groups are indicated. Employed sources are notarial protocols, consulates and customs records, judicial funds, the departmental Gazettes and official newspapers.

Key words: ports; import; merchant houses; merchant circuit.

Fecha de recepción: 4 de septiembre de 2013. Fecha de aceptación: 18 de marzo de 2014.

Am. Lat. Hist. Econ., año 22, núm. 1, enero-abril, 2015, pp. 85-114 


\section{INTRODUCCIÓN}

$\mathrm{E}$ 121 de agosto de 1874 el juzgado nacional de Cúcuta, durante un juicio por contrabando a la renta de aduana, se pronunció en contra de Mariano Delgado como introductor sin licencia de "unos retazos de tela extranjera", quien huyó al verse fiscalizado, abandonando dicha mercancía ante los guardas. ${ }^{1}$ En la misma década se anunciaba la llegada del periódico La Elegancia, que incluía figurines a la moda y estaba ilustrado con novelas. ${ }^{2}$ Se recomendaba la crema dentífrica solidificada y el perfume distinguido que no se parecía a aquellos de fabricación ordinaria. ${ }^{3}$ Además, el secretario de Hacienda y Fomento mencionaba el crecimiento en el sector de importación en la Aduana de Barranquilla, con un rendimiento que llegaba a más de medio millón de pesos. ${ }^{4}$

La anterior descripción refiere a la introducción clandestina y la importación legal de mercancías finas de origen extranjero, también manifiesta el entorno cotidiano que avanzaba conjuntamente con el movimiento mercantil registrado por los puertos más importantes de Colombia durante la segunda mitad del siglo XIX. Los puertos de Tumaco, Riohacha, Sabanilla (Barranquilla), Buenaventura, Santa Marta, Cartagena y Cúcuta, fueron destino de embarcaciones procedentes de los puertos de Liverpool, Grimsby, Manchester y Southampton en Inglaterra; El Havre, Saint Nazaire y Marsella en Francia; Bremen y Hamburgo en Alemania; Nueva York en Estados Unidos; Málaga, Cádiz y Barcelona en España. Con puertos de tránsito como la Guaira, Curazao, Kingston, La Habana, Maracaibo, Callao, Veracruz, Puerto Cabello, Panamá y Colón.

La importancia del puerto de Sabanilla fue tal que desempeñó un papel determinante. A comienzos del siglo XIX, Sabanilla fue el puerto marítimo utilizado por los comerciantes de Barranquilla, puesto que este era un pequeño puerto fluvial prácticamente sin acceso al mar por los bancos de arena de Bocas de Ceniza que dificultaban la navegación; de hecho, durante este periodo, se vio opacado por el tráfico de los puertos de Cartagena y Santa Marta. En 1877 su apertura le permitió convertirse en el principal puerto colombiano y la ciudad en un centro industrial y comercial dinámico, con una población de empresarios e inversionistas alemanes,

\footnotetext{
${ }^{2}$ Diario Oficial (1870, núm. 1819, p. 156). Archivo Histórico Regional, Bucaramanga, Colombia.

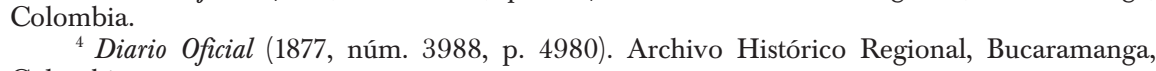
Colombia.
} Colombia.

${ }^{1}$ Diario Oficial (1874, núm. 3268, p. 2118). Archivo Histórico Regional, Bucaramanga, 
franceses, ingleses, sirios y libaneses. Esta transformación fue posible a partir de la apertura del puerto en la bahía de Sabanilla y de la línea del ferrocarril de Bolívar, que facilitó la comunicación con Barranquilla. El puerto de Sabanilla fue habilitado para cumplir las funciones de puerto marítimo y fluvial, además de facilitar las operaciones para controlar el comercio e impedir la introducción de mercancías ilegales (Correa, 2012, pp. 241-242; Laurent, 2008, pp. 413-417).

Así, llegaban mercancías importadas de una sociedad irrumpida por las modas externas y los artículos de lujo después de un largo viaje desde Europa y Estados Unidos para arribar a pequeños puertos en Santander, ${ }^{5}$ construcciones internadas en las montañas y en las confluencias de los ríos. Dos polos comerciales contribuyeron en la introducción de dichas mercancías hacia la región de Santander: al noreste, la aduana de Cúcuta servía de entrada al vecino país de Venezuela y su puerto de Maracaibo, y al norte, el puerto de Barranquilla constituyó una importante ruta de acceso al interior del país, dadas las ventajas de navegación que ofrecía el río Magdalena.

Las operaciones comerciales de importación quedaron registradas en diversos documentos pertenecientes a los consulados de Colombia en el exterior, en instrumentos notariales, en gacetas, diarios oficiales, periódicos y demandas judiciales. En este artículo se utilizará parte de esos documentos oficiales y civiles, con el objetivo de analizar el circuito mercantil conformado entre la importación de bienes de consumo, el entorno social y los puertos locales ubicados en Santander (Colombia) entre 1870 y 1900. Estos 30 años estuvieron marcados por el incremento de las operaciones mercantiles con el extranjero y por el surgimiento de nuevas casas comerciales. Actividades condicionadas principalmente a los ritmos del transporte fluvial y terrestre, $\mathrm{y}$ a los constantes cambios de rutas en la búsqueda de mejores condiciones en la superficie de los terrenos (Gutiérrez, 2012, p. 199).

A pesar de las diversas interpretaciones sobre los obstáculos políticos y sociales causados por las guerras civiles, el aislamiento de las regiones, la falta de adecuación de los puertos fluviales, la debilidad del comercio interregional o los elevados costos del transporte (Gutiérrez, 2012), se produjeron transformaciones notorias en el comercio de importación, evidenciadas principalmente a partir del aumento en la introducción de bienes de consumo. Para ampliar este argumento, primero se examinará la ubi-

${ }^{5}$ Los incipientes puertos fluviales y los medios de transporte (mulas u hombres) fueron condición necesaria para el movimiento económico interno del país, una realidad que poco se conoce teniendo en cuenta las numerosas investigaciones relacionadas exclusivamente con los intercambios externos. 
cación, organización y funcionamiento de los puertos locales. En segundo lugar se estudiarán las casas comerciales y los principales importadores. Finalmente, se indicará el tipo de objetos y mercancías de lujo introducidos por dichos importadores, los cuales se incorporaron a los diferentes grupos sociales.

\section{DE PUERTOS EXTRANJEROS A PUERTOS FLUVIALES LOCALES}

A mediados del siglo XIX el tráfico marítimo entre Colombia y los puertos extranjeros experimentó un importante crecimiento respecto a la importación de mercancías. Entre 1881 y 1883 las importaciones pasaron de 3000000 de pesos a más de 11000000 de pesos, aproximadamente (Ocampo, 1984, p. 143). Durante este periodo los ciclos de las importaciones dependían de las coyunturas de los mercados de exportación. La bonanza de las exportaciones de productos primarios como la quina y el café permitió la expansión de las importaciones. Sin embargo, con la desaparición de la quina y la caída de los precios del café durante la guerra de los Mil Días, disminuyó el intercambio con el extranjero y parte del flujo de las importaciones (Ocampo, 1984, p. 144).

En la década de 1870 se presentó un crecimiento acelerado de las importaciones reales debido, entre otras cosas, a la caída en los precios mundiales y el escaso dinamismo del comercio de exportación. El crecimiento de estas importaciones repercutió en el desarrollo de la industria textil y el avance de los transportes en Colombia. En el primer caso, la ampliación del consumo de textiles introdujo nuevos escenarios de mercado que impulsaron el avance de una industria moderna en Colombia. Desde el punto de vista del desarrollo de los transportes modernos, algunos autores (Gutiérrez, 2012; Ramírez y Pachón, 2006; Safford, 2010) han asociado más la aparición de la navegación a vapor por el río Magdalena con el comercio de importación que con el de exportación, debido al crecimiento de las importaciones reales. Lo anterior, unido al abaratamiento de la manufactura de metal, las inversiones estatales y el surgimiento del café, explican el desarrollo de los ferrocarriles durante el cambio de siglo (Ocampo, 1984, pp. 149-153).

Estas transformaciones, debidas al intercambio con los países europeos, fueron posibles con el ingreso de los vapores transatlánticos y el aumento de nuevas rutas comerciales con Europa (Ocampo, 1984, p. 161). Los vínculos comerciales colombianos, efectuados directa y regularmente con Europa y Estados Unidos, este último en asuntos de reexportación con Francia (Ocampo, 1984), estuvieron asociados con las principales líneas de vapores postales marítimas, como la West India \& Pacific Steam 
Ship Co. Ltd., la Compañía General Transatlántica (Compagnie Générale Transatlantique), la línea postal marítima conocida como la Mala Real Inglesa (Royal Mail Steam Ship Packet Co.), la Hamburguesa Americana (Hamburg Amerikan Line), la Harrison Line Co. y la Compañía Transatlántica Española.

La frecuencia de los intercambios y los enlaces con los puertos de escala en el Caribe aumentó de forma considerable a finales del siglo XIX. Así, antes de ingresar en las costas colombianas, los vapores transatlánticos provenientes de los puertos europeos hacían transbordo de mercancías en las diversas islas caribeñas. En el caso de los puertos de Liverpool y Southampton, en Inglaterra, las escalas frecuentes eran en los puertos de San Vicente, Barbada, Trinidad, Granada, St. Thomas, Puerto Príncipe, Kingston, Antigua, Saint Kitts, Jacmel, Colón, La Guaira, Puerto Cabello, Curazao, para finalmente llegar a los puertos de Santa Marta y Cartagena. Los puertos franceses de Saint Nazaire, Marsella y El Havre se conectaban con los puertos de Pointe á Pitre, Basse Terre, St. Pierre, Fort de France, Carúpano, Curazao, La Guaira y Puerto Cabello. La Compañía West India \& Pacific Steam Ship Co. Ltd. y la Compañía Atlas (Atlas Steam Ship Co.) procedente de Nueva York, ingresaban en primer lugar a los puertos de escala localizados en Greytown (Nicaragua), Puerto Limón (Costa Rica), antes de arribar a los puertos de Cartagena, Santa Marta y Riohacha. Por su parte, los vapores españoles Correos del Marqués de Campo se enlazaban en Santiago de Cuba y La Habana con puertos de escala en Nuevitas, Gibara, Baracoa, Kingston y Santa Marta. ${ }^{6}$ Las conexiones entre las mencionadas líneas permitían que principalmente el ingreso de los vapores al puerto de Sabanilla variara entre una y siete veces durante el mes (véase mapa 1$)^{7}$

Del promedio de buques que ingresaron al puerto de Barranquilla entre 1891 y 1892, según el Ministerio de Hacienda, 150 de ellos presentaron cargamentos que no correspondían totalmente con los sobordos enviados por los respectivos cónsules y los manifiestos remitidos por el administrador de la aduana. Lo mismo sucedió durante 1888 y 1889, época en la que un promedio aproximado de 300 buques que ingresaron al puerto presentaron las mismas inconsistencias. ${ }^{8}$ Una de las razones para que la aduana de Barranquilla presentara estas irregularidades se debió, en primer lugar, a la preponderancia que había alcanzado en relación con los puertos ma-

${ }^{6}$ Diario Oficial (1882, núm. 5352, pp. 10461-10462). Archivo Histórico Regional. Bucaramanga, Colombia.

${ }^{7}$ Diario Oficial (1882, núm. 5352, pp. 10461-10462). Archivo Histórico Regional. Bucaramanga, Colombia.

${ }^{8}$ Diario Oficial (1882, núm. 8975, pp. 1440-1443). Archivo Histórico Regional. Bucaramanga, Colombia. 
rítimos de Santa Marta y Cartagena; en segundo lugar, a la gran demanda de mercancías extranjeras, la aplicación de la legislación arancelaria, la corrupción de los empleados aduaneros, la inestabilidad política y la falta de instrumentos y espacios para controlar los ingresos. Por tanto, no es difícil afirmar que las compañías extranjeras también estuvieran involucradas en la introducción de mercancías ilícitas.

El envío de mercancías a puertos de pequeña escala aumentó de forma notable a finales del siglo XIX. Las mercancías procedentes de Hamburgo, Nueva York, Málaga y Génova se depositaban en consignación en el puerto de Maracaibo, como primer destino, para luego ser enviadas por el río Zulia hasta Encontrados, de allí a los puertos de Los Cachos, Villamizar y por el río Táchira en la frontera, hasta Cúcuta (Laurent, 2008, pp. 379380 y 406)..$^{9}$ Aun cuando la aduana representó un volumen de comercio exterior intermedio en comparación con las otras, esta llegó a registrar también una cantidad considerable de introducciones ilícitas. Contrabando de mercancías extranjeras procedentes de vías terrestres y fluviales, específicamente del río Táchira y de Maracaibo.

Entre septiembre y octubre de 1870 se enviaron a la aduana de Cúcuta 2617 bultos procedentes de Maracaibo con valor de 20770 pesos. ${ }^{10}$ En 1883 se enviaron al mismo destino 1125 bultos de vino seco con valor de 4482 pesos; 55 bultos de aceite de Kerosene con valor de 215.30 pesos; diez bultos de vino amargo con valor de 100 pesos; 49 bultos de brandy por 40 pesos; 49 bultos de vino vermouth por 352 pesos, y 350 bultos de harina de trigo por 20025 pesos. ${ }^{11}$ Con destino al puerto de Villamizar, en noviembre de 1877, 5629 bultos con valor de 189362.83 pesos. ${ }^{12}$ Entre agosto y noviembre de 1889, del mismo puerto salieron para Cúcuta, 11977 bultos procedentes de Nueva York; 2349 de Curazao; 887 de Birmingham; 1353 de Liverpool; 3681 de Manchester; 1625 de París; 241 de El Havre; 2169 de Burdeos, 73 de Marsella; 4260 de Málaga; 735 de Génova; 12550 de Hamburgo; 726 de Venezuela, y 67 de La Habana (véase mapa 2). ${ }^{13}$

\footnotetext{
${ }^{9}$ Sección República (Aduanas, manifiestos de importación, 1895-1918, fs. 1-3, carpeta 1, caja 3). Archivo General de la Nación. Bogotá, Colombia.

${ }^{10}$ Diario Oficial (1870, núm. 2098, p. 1278). Archivo Histórico Regional. Bucaramanga, Colombia; Diario Oficial (1870, núm. 2101, p. 1288). Archivo Histórico Regional. Bucaramanga, Colombia; Diario Oficial (1871, núm. 2130, p. 15). Archivo Histórico Regional. Bucaramanga, Colombia.

${ }^{11}$ Diario Oficial (1884, núm. 6164, p. 13715). Archivo Histórico Regional. Bucaramanga, Colombia.

${ }^{12}$ Diario Oficial (1878, núm. 4165, p. 5697). Archivo Histórico Regional. Bucaramanga, Colombia.

${ }^{13}$ Diario Oficial (1890, núms. 8125-8126, p. 685 y 688). Archivo Histórico Regional. Bogotá, Colombia.
} 


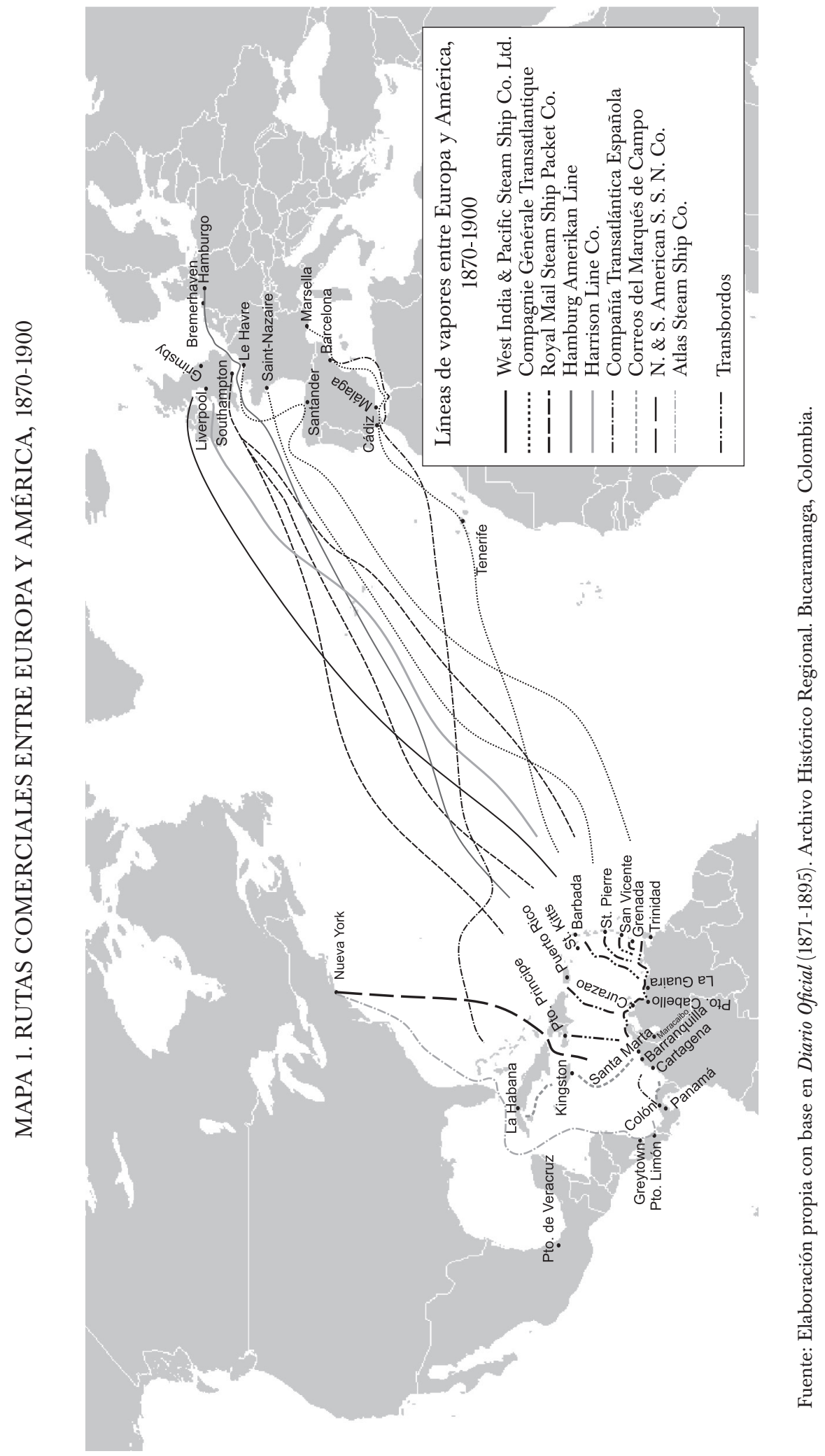




\section{MAPA 2. PUERTOS MARÍTIMOS Y FLUVIALES DE ACCESO A SANTANDER, COLOMBIA, 1870-1900}
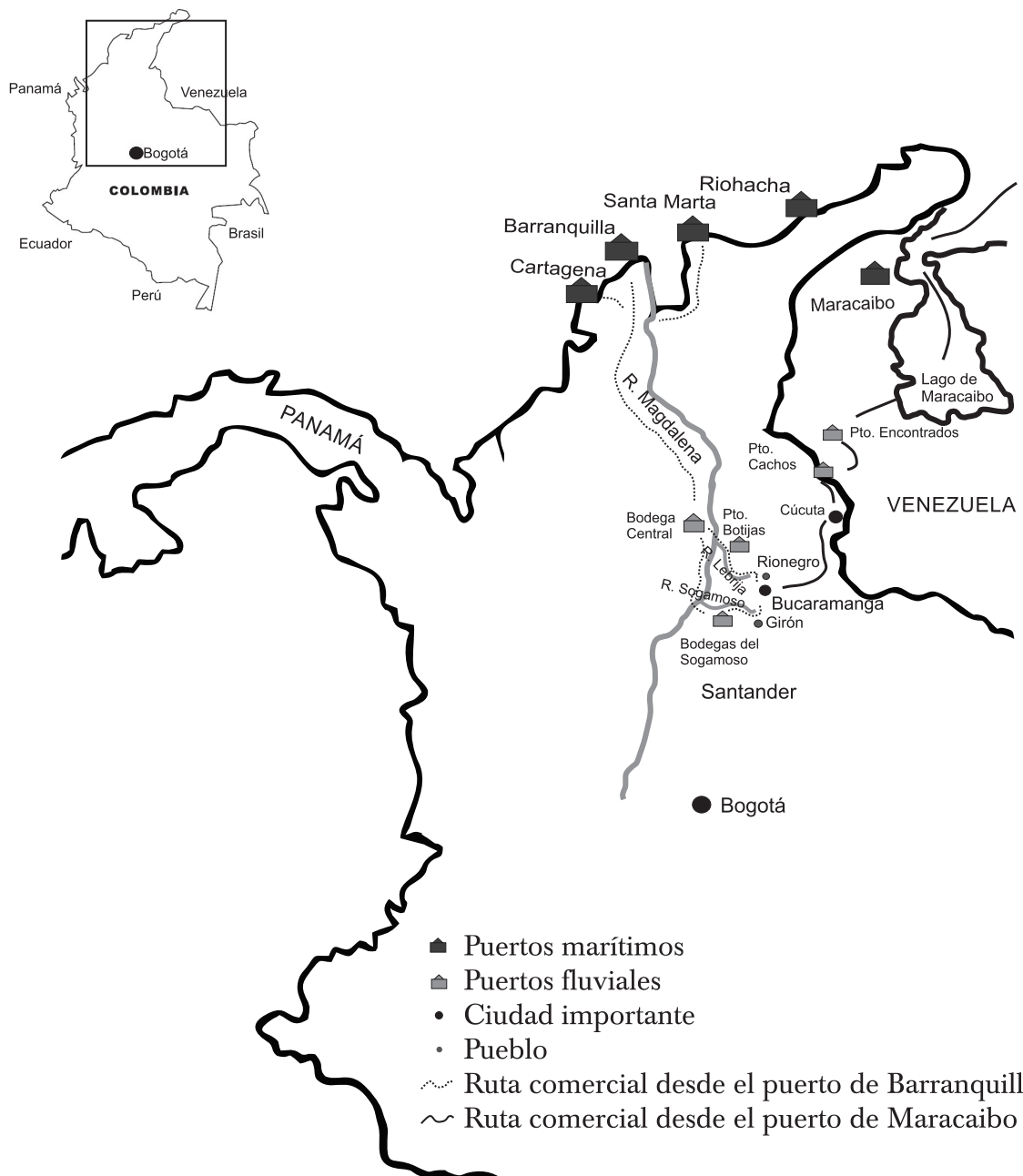

- Puertos marítimos

- Puertos fluviales

- Ciudad importante

- Pueblo

Ruta comercial desde el puerto de Barranquilla

$\sim$ Ruta comercial desde el puerto de Maracaibo

Fuentes: elaboración propia con base en Diario Oficial (1870-1892). Archivo Histórico Regional y Archivo General de la Nación, Bogotá, Colombia, y fragmento adaptado de J. Anesi, s. f., Colombia. [Cartelas con mapa físico y poblacional Archivo Guillermo Hernández de Alba]. (Colección Cartografía histórica, Fronteras y divisiones político administrativas, número topográfico C10897). Buenos Aires, Argentina. Recuperado de http://www.banrepcultural.org/blaavirtual/ cartografia/colombia-2 
Además de ser el punto de afluencia para la introducción de mercancías al interior de Santander, el puerto de Los Cachos concentró los intereses de varios empresarios y políticos de la región. En 1865 se organizó una compañía con el objetivo de construir un camino entre Cúcuta y dicho puerto. Durante 1876 sobre la vía se construyó el llamado Ferrocarril de Cúcuta, producto de la asociación de comerciantes y agricultores tanto venezolanos como colombianos (Pabón, 2011, pp. 19, 67, 89, 102), convirtiéndose aquella vía en la más apropiada para continuar el comercio entre los dos países. Vía Maracaibo se llegaba a Guayabo, de allí al puerto de Villamizar por medio de lanchas o bongos, para continuar hasta Cúcuta en ferrocarril. ${ }^{14}$ Los comerciantes manifestaban la conveniencia de esta vía en relación con la utilizada desde Barranquilla, la cual llegaba hasta Bodega Central y el puerto de Botijas (más adelante Puerto Santos), sobre el río Lebrija, para terminar en mulas hasta Bucaramanga.

Sin embargo, otros comerciantes se quejaban por los perjuicios ocasionados al construir el ferrocarril por la vía hacia Venezuela, debido a que se monopolizaría el comercio con dicho país y con el puerto de Maracaibo, señalando los constantes cierres de la frontera por el gobierno venezolano. Insistían también en las mejores condiciones que ofrecía la circulación entre el río Magdalena y el puerto de Barranquilla, señalando además, el decreto que en 1869 el Estado había firmado y que manifestaba la apertura de un camino de herradura que comunicaba a los valles del Cúcuta con el río Lebrija y el río Magdalena, como una vía propia y nacional que comunicara con el puerto de Barranquilla. A pesar de ser un proyecto ambicioso, la vía planeada evitaría articular esta empresa con la del ferrocarril del Táchira y los problemas del comercio con la frontera venezolana. Se desviaría al puerto de Barranquilla y vincularía plazas comerciales como Ocaña, Girón y Bucaramanga ${ }^{15}$ a su vez, se prolongaría el ferrocarril de Cúcuta hasta Tamalameque, región del río Magdalena caracterizada por la riqueza agrícola. ${ }^{16}$

La navegación a vapor por el río Magdalena comenzó con vapores traídos de Inglaterra en la segunda década del siglo XIX. El río favoreció la integración de los puertos atlánticos de Cartagena, Santa Marta y Barranquilla con el espacio andino, llegando en primer lugar a algunos emplazamientos como Mompox y Magangué, arriesgándose algunas veces hasta

${ }^{14}$ Sección República (Aduanas, administración-informes; 1873-1914, fs. 106-109, carpeta 1, caja 2). Archivo General de la Nación. Bogotá, Colombia.

${ }^{15}$ Diario Oficial (1870, núm. 1942, p. 649). Archivo Histórico Regional. Bucaramanga, Colombia, y Diario Oficial (1871, núm. 2144, p. 69). Archivo Histórico Regional. Bucaramanga, Colombia.

${ }^{16}$ Diario Oficial (1896, núm. 10079, p. 678). Archivo Histórico Regional. Bucaramanga, Colombia. 
los puertos de Caracolí, cerca de Honda, para llevar mercancías hasta Bogotá. Después de 1850 llegaban a otros puertos tales como Calamar, Zambrano, Barrancabermeja, Bodega Central, Puerto Nacional, Nare y Puerto Berrío, aumentando así la capacidad de transporte para finales de 1870.

La navegación se veía afectada por la escasez de desembarcaderos, los trechos de poca profundidad o aquellos invadidos por trozos de maderas y vegetación superficial (Gutiérrez, 2012, pp. 157-161). El funcionamiento de los puertos fluviales dependía de la articulación con los sistemas de caminos que los conectaban con las regiones y centros de producción distantes geográficamente.

En Santander, tanto el gobierno, representado por la Junta de Fomento, como los miembros del comercio de la ciudad de Bucaramanga se interesaron por la movilidad y el mejoramiento de los almacenes y bodegas, con el fin de consolidar los puertos como centros adecuados para la recepción de las mercancías provenientes del exterior. Dichos puertos, localizados en pequeños caseríos, poseían varios almacenes para el acopio de la sal, los productos agrícolas de exportación y para las mercancías importadas. Algunos se distinguían por ser tambos de paja o palma, algunos construidos todavía de madera y otros cimentados de hierro y zinc, con estantillos de palos con amarros de alambre, sin desagües y expuestos a las goteras durante los fuertes inviernos. ${ }^{17}$

Con el crecimiento progresivo de la actividad comercial, los puertos fueron bastante concurridos, el auge era tal que muchas veces se recurría al arrendamiento de casas particulares para guardar las mercancías. ${ }^{18}$ En algunos casos, la gran afluencia de mercancías sin dueño conocido que autorizara la salida de las cargas, ocasionaba la acumulación excesiva en las bodegas y en los puertos, siendo en tiempos de cosecha la época con mayor incremento (Avellaneda, 1999, pp. 64-66). Circunstancias que ocasionaban el alza de los fletes por la escasez de mulas y la lenta movilización, provocando retrasos que frecuentemente llegaban a más de dos meses.

El camino de Lebrija era uno de los trayectos comerciales en Santander, punto de conexión entre Bucaramanga, Girón y Rionegro con el río Lebrija, el río Magdalena y, más adelante, el puerto de Barranquilla. Dicho camino padeció la mayor parte del tiempo de las pendientes y mesetas adyacentes que lo convirtieron en una serie de vericuetos incorporados a

\footnotetext{
${ }^{17}$ Bodegas en su mayoría construidas de paredes de tierra y con techos de hierro galvanizado contra incendios. Gaceta de Santander (fondo Publicaciones Oficiales, 1898, núm. 3272), y Gaceta de Santander (fondo Publicaciones Oficiales, 1897, núm. 3175, pp. 517-518). Archivo Histórico Regional. Bucaramanga, Colombia. Semanario El Posta (fondo Revistas, 1895, núm. 46, p. 525). Archivo Histórico Regional, Bucaramanga, Colombia.

${ }^{18}$ Gaceta de Santander (fondo Publicaciones Oficiales, 1880, núm. 1377, p. 66). Archivo Histórico Regional. Bucaramanga, Colombia.
} 
los innumerables ríos y quebradas. Dos compañías comerciales monopolizaron dicha ruta: en el puerto de Barranquilla los comisionistas A. Pérez y Cía. se encargaban de gestionar los detalles de la descarga de manos de los representantes de las compañías extranjeras (Ocampo, 1984, pp. 175-177), de las condiciones y el estado de las mercancías para proceder a embarcarlas de nuevo y despacharlas por vapor por el río Magdalena con destino a Bodega Central. Allí eran recibidas por los comisionistas E. López \& Navarro para ser transportadas a la Estación Santander y al puerto de Botijas ${ }^{19}$ por medio de lanchas de vapor y pequeñas embarcaciones. ${ }^{20}$ Otras compañías de navegación de menor participación fueron Pacheco \& Cía. y M. Q. Jannaccone \& Ramón B. Salcedo. ${ }^{21}$

En cuanto al movimiento comercial por el río Sogamoso se encontró una exigua información en 1891 sobre la liquidación de la compañía denominada Concha y Liévano. Dicha empresa de embarcaciones, particularmente de canoas sobre el río Sogamoso, realizaba trayectos diarios desde El Pedral o Bodega de Sogamoso hasta Puerto Marta o Colorado y viceversa. ${ }^{22}$

El transporte de mercancías de las ciudades de Girón y Bucaramanga a los puertos sobre los ríos Sogamoso, Lebrija o Magdalena, demandaba pago de peajes, de bodegaje, y de comisiones durante el recibo y el despacho. La cuantía aumentaba con el cobro del pontazgo, teniendo en cuenta la gran cantidad de puentes localizados entre el puerto de Botijas y Bucaramanga. Dos ejemplos explican la poca inversión en su mantenimiento, tal como se observó con los puentes sobre el río Rionegro y el río Suratá, que durante el invierno se deterioraban de manera considerable. ${ }^{23}$

Para finales del siglo XIX, las bodegas aún eran escasas en los puertos y en las riberas de los caminos. Una legua más delante y en la ribera opuesta, el puerto de Botijas fue reemplazado por Puerto Santos. Sin embargo, este amenazaba ruina por el desplome, consecuencia de la mala construcción

${ }^{19}$ Fondo Wilches (caja 2, documentos sueltos). Archivo Histórico Regional. Bucaramanga, Colombia.

${ }^{20}$ Notaría Primera de Bucaramanga (1898, t. 4, caja 215, núm. 737, fs. 2070r-2072v, núm. 747, fs. 2086r-2088v; núm. 753, fs. 2102v-2103r; núm. 756, fs. 2107r-2120v, 1898, t. 5, caja 216, núm. 757, fs. 2121r-2122v, núm. 960, fs. 2902r-2903v; Archivo Histórico Regional. Bucaramanga, Colombia. También véase Sector Civil Ejecutivo (Fondo Judicial de Bucaramanga, 1883, caja 106, fs. 31-32). Bucaramanga, Colombia. Colombia.

${ }^{21}$ Diario Oficial (1887, núm. 7057, p. 592). Archivo Histórico Regional. Bucaramanga,

${ }^{22}$ Civil Ejecutivo (Fondo Judicial de Bucaramanga, 1891, caja 110, fs. 6, 9,). Archivo Histórico Regional. Bucaramanga, Colombia.

${ }^{23}$ Fondo Wilches (1886, Relación del pago de los derechos de peaje y pontazgo, caja 2, documentos sueltos). Archivo Histórico Regional, Bucaramanga, Colombia; Gaceta de Santander (fondo Publicaciones Oficiales, 1875, núm. 992, p. 184). Archivo Histórico Regional. Bucaramanga, Colombia, y Informe (1870, pp. 9-11), Archivo Histórico Regional. Concepción, Colombia. 
del terraplén artificial sobre el que fue armado. Para 1895, en los puertos de Marta y Puerto Santos hacía falta un armazón para que los arrieros cargaran o descargaran los bultos cuando llovía, además de una ramada en mejores condiciones, grande y capaz para pesar los cargamentos. ${ }^{24}$

Las bodegas para depositar las mercancías en la aduana de Cúcuta presentaron varias dificultades por la estrechez del espacio. La falta de bodegas era el pretexto para que los comerciantes evadieran el pago por la introducción de artículos, situación que se facilitaba al depositar en almacenes particulares donde no pagaban los derechos exigidos por la aduana. Las quejas eran constantes teniendo en cuenta el deterioro de la infraestructura, los inconvenientes con las polillas y el comején que destruía las puertas de madera, provocando inseguridad en los objetos guardados en ellas. Lo mismo sucedía con el puerto de Los Cachos, cuya construcción de la aduana era un espacio reducido, carente de un piso firme, con apariencia de rancho y en mal estado (Laurent, 2008, pp. 430- 432).

Los pequeños puertos, como el de Los Cachos, no se vieron estructuralmente afectados por la cantidad de bultos que ingresaron desde mercados externos. En el informe enviado por el Consulado de Colombia en Maracaibo, se evidencia el movimiento mercantil en 1869, fecha en la cual ingresaron 26 buques de diversas nacionalidades al puerto de Maracaibo. ${ }^{25}$ En noviembre de ese mismo año y hasta mayo de 1870 fueron despachadas para el puerto de Los Cachos, en promedio, entre doce y 17 embarcaciones o bongos mensualmente, con un cargamento de 3650 bultos de mercancías extranjeras. Este ejemplo sugiere que los hábitos, las costumbres y las necesidades viciadas por las prácticas sociales muy tradicionales aún se mantenían, fluctuando entre lo moderno y lo antiguo, mediadas por ambientes desordenados, ilegales y rudimentarios.

\section{LAS CASAS IMPORTADORAS Y LOS COMERCIANTES}

Un elemento importante en el circuito comercial de importación en Santander fue la conformación de casas comerciales vinculadas a las familias más influyentes de la ciudad de Bucaramanga, emparentadas entre sí a través de matrimonios concertados. Durante la década de 1860, los comerciantes de Bucaramanga se limitaban a comprar productos importados a comerciantes de Cúcuta, Barranquilla, Magangué y Bogotá, que en su

\footnotetext{
${ }^{24}$ Semanario El Posta (fondo Revistas, 1895, núm. 53, pp. 553-554). Archivo Histórico Regional, Bucaramanga, Colombia.

${ }^{25}$ Diario Oficial (1870, núm. 1792, p. 42; núm. 2004, p. 897). Archivo Histórico Regional. Bucaramanga, Colombia.
} 
mayoría contaban con los recursos y relaciones necesarios para adquirir mercancías europeas en plazas como Manchester, Glasgow, Edimburgo, Birmingham, Sheffield y Londres (Duque, 2005, p. 162).

Entre 1850 y 1860 se hicieron en Bucaramanga las primeras introducciones de artículos extranjeros. Dichas mercancías consistían básicamente en telas, con las cuales surtían a almacenes minoristas de la misma ciudad, de Girón y Piedecuesta (Duque, 2005, p. 157). Durante esta década se comenzó a formar un gremio de comerciantes locales y extranjeros, especialmente alemanes y algunos italianos, quienes monopolizaron el comercio importador-exportador. Procedentes de países europeos, en donde tenían amplios nexos comerciales e industriales, los extranjeros introdujeron capitales y ampliaron su área de influencia para el desarrollo de la actividad mercantil. Para finales del siglo XIX, los comerciantes de Bucaramanga comenzaron a comprar, vender y relacionarse directamente con casas comerciales inglesas, alemanas y estadunidenses. ${ }^{26}$

Santander concentró una parte importante de comerciantes que terminaron coincidiendo en las prácticas monopólicas e incorporando funciones políticas en el movimiento comercial. Las estrategias utilizadas dependían de los matrimonios concertados, las asociaciones financieras y los favores políticos. Los pioneros en el comercio bumangués fueron Juan Crisóstomo Parra, David Puyana, David Figueroa, Luis Francisco Ogliastri, Joaquín París, Pedro María Peralta, Cristóbal y Enrique García, Pablo Antonio Valenzuela, Encarnación Azuero, Santafé Cadena, Geo von Lengerke, Adolfo Harker y Modesto Ortiz (Duque, 2005, p. 155). Entre 1860 y 1910 aumentó el número de casas comerciales en Bucaramanga, algunas de ellas producto de fusiones entre los primeros comerciantes con aquellos recién establecidos como Koppel \& Schloss, Victor Paillié, Réyes González \& Hnos., Ignacio Cadena, Lorent, Keller \& Cía., Paul Polko, Minlos Breuer \& Cía., Trinidad Parra de Orozco, Benito Ordóñez, Manuel Cortissoz, y C. P. Clausen. ${ }^{27}$

La estrategia de estos comerciantes consistía en asociarse para realizar importaciones con el fin de fusionar capitales y evitar el costo en el pago de los impuestos de aduanas. ${ }^{28} \mathrm{~A}$ su vez, se apoyaban bajo la figura de la fianza para respaldar los derechos de importación, principalmente por el ingreso de mercancías extranjeras en la aduana de San José de Cúcuta.

${ }^{26}$ Sección Ejecutivo (fondo Judicial de Bucaramanga, caja 107, fs. 3v-4r, 1886). Archivo Histórico Regional. Bucaramanga, Colombia, y Semanario El Posta (fondo Revistas, 1895, núms. 46 y 53). Archivo Histórico Regional. Bucaramanga, Colombia.

${ }^{27}$ Fondo Wilches (caja 2, documentos sueltos). Archivo Histórico Regional, Bucaramanga, Colombia.

${ }^{28}$ Sección Civil Ejecutivo (fondo Judicial de Bucaramanga, caja 105, f. 1, 1877). Archivo Histórico Regional, Bucaramanga, Colombia. 
Una de las primeras sociedades se denominó Puyana \& Ogliastri, formada por Luis Francisco Ogliastri y David Puyana, cuyas operaciones iniciales consistían en la exportación de café hacia las casas extranjeras C. G. Meier \& Cía. de Londres, Punderford \& Jenney de Nueva York y Santamaría \& Cía. de Liverpool (Duque, 2005, p. 162).

Koppel \& Schloss, propiedad de S. F. Koppel y Carlos Schloss, se convirtió en una de las casas comerciales más reconocidas de Bucaramanga y Bogotá. Se hicieron cargo de la casa que tenían Leopoldo y Daniel Schloss en Bogotá, cuando estos viajaron a Inglaterra para fundar la casa comercial Schloss Brothers de Londres, intermediaria entre Inglaterra y Alemania para despacharles mercancías hacia la aduana de Barranquilla. Más adelante se asociaron con Adolfo Harker formando la casa Koppel \& Schloss \& Cía. (Duque, 2005, p. 163). ${ }^{29}$

Los alemanes siempre mantuvieron vínculos cercanos con familias reconocidas de Bucaramanga. Geo von Lengerke, junto a su sobrino Paul G. Lorent, fundó la compañía Lengerke \& Lorent. A la muerte de Lengerke en 1882, Lorent fundó junto con Carlos Keller y Gustavo Wolkmann la casa Lorent, Keller \& Cía. para introducir por la Aduana de Barranquilla mercancías provenientes de Inglaterra ${ }^{30} \mathrm{Al}$ separarse de Keller, conformó en 1893 la sociedad Lorent \& Volkman dedicada también al comercio de importación (Guerrero y Avellaneda, 2002, pp. 14-19).

Otros alemanes destacados fueron Hermann Hederich, quien junto con Christian Goelkel fundaron en 1873 la compañía Hederich \& Goelkel. La familia Valenzuela se unió a la familia alemana Minlos Breuer a través de Carlina y Amelia Valenzuela, esposas de Emilio Minlos Motovio y Felipe Hakspiel, respectivamente. Minlos Breuer \& Cía. fue una de las casas más reconocidas de Maracaibo, con sucursal en Bucaramanga durante la década de 1880. La compañía fue creada el 31 de agosto de 1883 por Enrique Eduardo Breuer, Augusto Adolph Emel Minlos, Jens Nicolassen Möller, Federico Guillermo Birtuir, J. Sue Lalleman, Jorge Hesselman, Christian Federich Witzke y Federico Minlos (Duque, 2005, pp. 165-166; Espínola, 2006, pp. 3-5).

Hacia 1888, la firma ingresó algunas mercancías de importación, entre las que se encontraban 97 bultos de mercancías secas, camisas hechas de algodón sin nada de lino, pieles curtidas no manufacturadas, calzado hecho, sombreros y pavitas de paja, artículos de ferretería, quincallería, goma arábiga (Espínola, 2006, pp. 3-5, 10). La compañía se disolvió el 30

${ }^{29}$ Diario Oficial (1892, núm. 8883, pp. 1015-1016). Archivo Histórico Regional. Bucaramanga, Colombia y Diario Oficial (1896, núm. 9026, p. 1680). Bucaramanga, Colombia. Colombia.

${ }^{30}$ Diario Oficial (1892, núm. 8883, pp. 1015-1016). Archivo Histórico Regional, Bucaramanga, 
de diciembre de 1895 para constituir otras dos casas comerciales: Minlos, Witzke \& Co. y Breuer, Möller \& Co. Su sede principal estaba en Hamburgo, con sucursales en Maracaibo y San Cristóbal, Venezuela, y San José de Cúcuta, Bucaramanga y Barranquilla, Colombia (Espínola, 2006).

Breuer, Möller \& Cía. se destacó por mantener negocios en el puerto de Barranquilla y en la frontera venezolana. Desde Nueva York, pasando por Maracaibo y el río Táchira, enviaban mercaderías a lomo de mula con destino a la Aduana de Cúcuta. ${ }^{31} 21$ fardos, incluyendo telas de algodón de diversas clases, colores, texturas y ordinarias, listados, zarazas, madapolán, muselinas, merinos, hilo de algodón, ${ }^{32}$ procedentes de Liverpool con destino a la Aduana de Barranquilla, fueron remitidos por Daniel Maccabe para su casa comercial. También, Neuss, Hesslein \& Co. remitieron desde Nueva York quince fardos de telas de lonas y zarazas de colores. ${ }^{33}$ Durante 1892, 1893 y 1896 fueron despachados a través de la aduana de Barranquilla para la compañía 56 bultos procedentes de Inglaterra. ${ }^{34}$ En 1913, L. G. Berndes \& Cía. remitieron procedente de La Habana una caja de tabacos en cigarro. ${ }^{35}$

En Bucaramanga también prosperaron algunas compañías constituidas por familias locales, entre ellas Cadena \& Hnos., García \& Hnos., Vargas Hnos., Mantilla Hnos., y Ogliastri Hnos., fundada por Roque, Julio y Jorge, hijos de Luis Francisco Ogliastri (Duque, 2005, p. 161). En 1882, otra compañía reconocida en Táchira y Bucaramanga se denominó Foción Soto y Cía., su fundador era un destacado importador de mercancías por la Aduana de Cúcuta y presidente de la "Compañía del camino al puerto de San Buenaventura (puerto de Villamizar)". ${ }^{36}$

Entre 1892 y 1896 se observó una mayor participación de los comerciantes de Santander y un aumento del número de introducciones por el puerto de Barranquilla; entre estos destacó la sociedad Lorent \& Volk-

\footnotetext{
${ }^{31}$ Sección República (Aduanas, manifiestos de importación, 1898-1914, f. 23, carpeta 2, caja 5). Archivo General de la Nación. Bogotá, Colombia.

${ }^{32}$ Sección República (Aduanas, manifiestos de importación, 1907-1917, ff. 18, 124, carpeta 1, caja 5). Archivo General de la Nación. Bogotá, Colombia.

${ }^{33}$ Sección República (Aduanas, manifiestos de importación, 1907-1917, f. 109, carpeta 1, caja 5). Archivo General de la Nación. Bogotá, Colombia.

${ }^{34}$ Diario Oficial (1892, núm. 8883, pp. 1015-1016). Archivo Histórico Regional, Bucaramanga, Colombia; Diario Oficial (1893, núm. 9101, p. 325). Archivo Histórico Regional. Bucaramanga, Colombia; Diario Oficial (1896, núm. 9026, p. 1680). Archivo Histórico Regional. Bucaramanga, Colombia, y Diario Oficial (1895, núm. 9737, pp. 417-419). Archivo Histórico Regional. Bucaramanga, Colombia.

${ }_{35}^{35}$ Sección República (Aduanas, manifiestos de importación, 1907-1917, f. 126, carpeta 1, caja 5). Archivo General de la Nación. Bogotá, Colombia.

${ }^{36}$ Sección República (Archivo Histórico Regional, 1847-1924, fs. 46-49, caja 6). Archivo General de la Nación. Bogotá, Colombia. Véase también Diario Oficial (1886, núm. 6778, p. 883). Archivo Histórico Regional, Bucaramanga, Colombia.
} 
mann, Koppel Schloss \& Cía. y Julio \& Enrique Silva, la cual fue sucesora de la compañía Estanislao Silva e Hijos creada en 1891 (Guerrero y Avellaneda, 2002, pp. 14-19). También, la sociedad Reyes González \& Hnos., fundada el 21 de septiembre de 1882 por los hermanos y socios Eleuterio, Florentino y Reyes González. Un año antes de fundar la sociedad, los hermanos González se unieron con el comerciante de Cúcuta Guillermo Forero Barreto para crear González \& Forero, cuyo propósito fue "especular en toda clase de negocios relacionados con la introducción y comercialización de drogas al por mayor y detal" (Duque, 2005, pp. 166, 168). Otra sociedad comercial local se denominó Trinidad Parra de Orozco \& Cía. formada por el cartagenero Nicolás Genaro Orozco y su esposa Trinidad Parra Quintero, hija y heredera del comerciante santandereano Juan Crisóstomo Parra (Duque, 2005).

De igual manera, se manifiesta el fortalecimiento de los vínculos comerciales entre dichos importadores y las casas extranjeras. Muestra de ello fue la conexión entre la sociedad F. Chagneau \& Co. y Benito Ordóñez e hijo, de Bucaramanga, donde el primero le remitió vinos de diversos tipos procedentes de Burdeos. ${ }^{37}$ También, el caso de C. P. Clausen, fundador de la cervecería Clausen en Bucaramanga, quien mantenía negocios comerciales con Alemania y Liverpool a través de la casa W. Duff \& Co. ${ }^{38}$

Otro caso fue el de Julius Rudert, quien envió diferentes tipos de mercaderías desde Hamburgo para Manuel Cortissoz de Bucaramanga, este último, judío nacido en Curazao, era socio de la casa barranquillera A. Wolff \& Cía. En 1885 fundó la Compañía Minera de Bolívar y Santander y en 1877 la sociedad comanditaria M. Cortissoz \& Co., con diversas sedes, entre ellas la de Lima -desde donde le enviaban a consignación en los vapores procedentes de Nueva York, variedad de mercaderías extranjeras para circular al interior de Santander, lugar escogido para establecer gran parte de sus negocios comerciales (Duque, 2005, pp. 167, 171; Ramírez, 2009). ${ }^{39}$

En cuanto al comercio minoritario, este contribuyó al aumento de mercancías baratas que terminaban en casas de las diversas clases sociales y en los almacenes de comerciantes con menos capitales, como se observa en la siguiente declaración: "yo tenía á [ $\mathrm{sic}$ principios de este año en mi casa propia de habitación del barrio de Quebrada del oro, en esta ciudad,

\footnotetext{
${ }^{37}$ Sección República (Archivo Histórico Regional, 1807-1917, f. 3, carpeta 1, caja 5). Archivo General de la Nación. Bogotá, Colombia. Véase también Diario Oficial (1895, núm. 9773, pp. 473476). Archivo Histórico Regional. Bucaramanga, Colombia.

${ }^{38}$ Sección República (Archivo Histórico Regional, 1907-1917, f. 63, carpeta 1, caja 5). Archivo General de la Nación. Bogotá, Colombia. Véase también Diario Oficial (1892, núm. 8883, pp. 1015-1016). Archivo Histórico Regional. Bucaramanga, Colombia.

${ }^{39}$ Sección República (Archivo Histórico Regional, 1907-1917, fs. 54, 97 carpeta 1, caja 5). Archivo General de la Nación. Bogotá, Colombia.
} 
una tienda de pulpería con efectos del país, mercancías extranjeras y algunos muebles del uso de la misma tienda". ${ }^{40}$

$\mathrm{El}$ auge de comerciantes que compraban y vendían a gran escala y aquellos que compraban y vendían al menudeo, movilizándose entre las ciudades ${ }^{41}$ favoreció el creciente ingreso de mercancías sueltas que no registraban pago de peajes ni ingreso a los puertos. Al estar fuera de las estadísticas oficiales, esta acción de introducir mercancías ilegalmente y sin el aumento de impuestos, permitió el crecimiento de ventas informales de mercancías baratas. Este tipo de transacciones manifiestan no sólo la frecuencia de los negocios, sino los itinerarios y las prácticas comunes de los comerciantes, quienes muchas veces terminaban en estado de insolvencia por el deficiente manejo de los negocios y por el incumplimiento de los créditos. ${ }^{42}$ Según Braudel (1993), se trata de un

conjunto de movimientos económicos que supone el funcionamiento de toda sociedad [...] incluyendo tanto elementos como instrumentos de la circulación: los caminos, los puertos, el medio de transporte, las mercancías transportadas, las tiendas, los mercados, las ferias, los intercambios mercantiles, la moneda en movimiento, el crédito, los diversos procesos del comercio y, naturalmente, los hombres, sus actos, sus desplazamientos (p. 240).

Los decomisos de productos importados durante el siglo XIX, tales como textiles, manufacturas, cigarrillos, licores, jabones, lozas, zapatos, pomadas, sombreros, papel, perfumes y relojes de plata ingleses, fueron los que más se distinguieron de entre los bienes que se pretendía introducir de contrabando, por el alto valor que tenían que pagar dichos productos para ser importados (Laurent, 2008, pp. 85, 302). Consecuencia de ello, fue la venta de "mercancías, batan, chucherías" y otros objetos de comercios que se vendían junto a mulas, muletos, caballos, ganados, en las ferias. Mercaderías atractivas en comparación con los bienes locales. ${ }^{43}$

${ }^{40}$ [Contrato de compraventa y posterior demanda de unos efectos de tienda]. Sección Civil Ejecutivo (fondo Judicial de Bucaramanga, caja 116, fs. 1r-6r, 1895). Archivo Histórico Regional. Bucaramanga, Colombia.

${ }^{41}$ Como el caso de Ricardo Uribe, quien no tenía domicilio fijo "pues como su profesión es comprar en el distrito de Lebrija para vender en esta ciudad y comprar aquí [Bucaramanga] otros artículos para venderlos allí, un poco reside en Lebrija y otro poco en Bucaramanga”. Sección Civil (fondo Judicial de Bucaramanga, caja 97, f. 8, 1885). Archivo Histórico Regional. Bucaramanga, Colombia.

${ }^{42}$ Sección Civil Tercerías (fondo Judicial de Bucaramanga, caja 3, f. 1). Archivo Histórico Regional. Bucaramanga, Colombia.

${ }^{43}$ Feria anual de Labateca en 1875, Informe (1875, pp. 70-71). Archivo Histórico Regional, Bucaramanga, Colombia. 
Desde el puerto hasta el lugar de destino, las mercancías eran vendidas en los largos trayectos que comunicaban a las aduanas con las regiones del interior. La introducción ilegal permitía que las diversas clases tuvieran acceso a dichos objetos, puesto que este comercio fue una práctica social que no distinguía nivel ni agrupaciones comerciales. Por tanto, el ingreso de productos extranjeros no sólo mudó las leyes y normas oficiales, sino que también transformó los modos y tradiciones a una dinámica socioeconómica que con el tiempo fue transformándose.

En relación con los perfiles de los contrabandista, Laurent (2008) proporcionó para el periodo de 1821 a 1850 información sobre los extranjeros sospechosos de la práctica de contrabando, destacándose entre ellos: ingleses, franceses, holandeses, españoles, estadunidenses y canadienses, con profesiones que iban desde agentes comerciales hasta capitanes de barco, residentes en Cartagena y conocedores de las leyes nacionales. En el caso de los contrabandistas nacionales, la autora encontró que dichos personajes no figuraban como residentes de la Costa Caribe, indicando la presencia de labradores, tejedores y jornaleros de San Gil (Santander), un comerciante y un arriero también en Santander, algunos vecinos y residentes en Mompox, y un dueño de tienda en Gachancipá, Bogotá y Rionegro, es decir, pequeños y medianos comerciantes, labradores y arrieros o conductores. Comerciantes que se enriquecieron no sólo por sus negocios legales sino también por los ilegales.

Por su parte, el comercio interregional dependía de una producción local sometida a los altos costos del transporte y las pocas vías de acceso al río Magdalena. En las regiones del interior se percibía de forma superficial el cambio hacia la modernidad en términos de administración política y económica, sobre las cuales las instituciones poco se habían transformado y en donde la infraestructura necesaria para la circulación comercial estaba sujeta a la inversión irregular en vías de comunicación como carreteras y líneas férreas. Así, la inclusión a nuevos mercados extranjeros resultaba de mayor utilidad para el gobierno, ya que estimulaba el consumo masivo de los productos extranjeros en las diversas clases sociales con el fin de amortizar deudas, garantizadas con el producto de las rentas de peajes de mercancías y de aguardientes (García, 1982, p. 372).

Para el caso de Santander, los peajes más importantes se encontraban en la vía que conducía de Maracaibo a Cúcuta, y de allí se dirigía hacia Bucaramanga, núcleo de confluencia de varias vías de comunicación. Los caminos hacia el río Magdalena por lo general eran los más importantes, ya que ofrecían, para la mayor parte de la población, la comunicación más corta con la costa y con el exterior (Carreño, 2007). La región presentaba una marcada influencia monopólica por parte de un grupo de comerciantes que operaba los principales negocios comerciales bajo su interés parti- 
cular, manipulando una esfera de desarrollo concentrada exclusivamente en dicha ciudad. Estas circunstancias motivaron que en 1876 se impulsaran dos proyectos para vincular comercialmente a Cúcuta y Socorro, capital del estado de Santander. ${ }^{44}$

La composición de los caminos impulsada por el gobierno pretendía aumentar el tránsito comercial de las zonas intermedias entre Cúcuta y Bogotá. Se trazó una vía que conectara con Pamplona, Bucaramanga, Socorro y Monte del Moro con el propósito de proveer también con los artículos básicos de consumo a los principales centros de mercados del estado de Boyacá. ${ }^{45}$ Por medio de la Aduana de Cúcuta, el Socorro se abastecería de mercancías extranjeras, como las telas blancas de algodón vendidas a precios muy inferiores en comparación con los precios de los mercados de Bogotá, debido a que las mercancías y artículos europeos que se vendían en los pueblos circunvecinos a Vélez y el Socorro eran proveídos del mercado bogotano a elevados costos (Laverde, 1889, p. 29). El proyecto, además, buscaba un acercamiento comercial entre la región de García Rovira y Cúcuta, teniendo en cuenta la importancia de la Aduana localizada en esta última ciudad (Laurent, 2008) (véase esquema 1).

\section{LA SOCIEDAD Y LOS BIENES DE CONSUMO}

En los informes de los presidentes a la asamblea legislativa del Estado de Santander se observa que el objetivo principal de sus proyectos fue promover mudanzas en la instrucción pública, fomentar la agricultura, la construcción de los ferrocarriles, la reconstrucción de caminos y ciudades, y facilitar contratos para impulsar la navegación a vapor. Los cambios incluían también la transformación de las costumbres, de los hábitos de alimentación y vestimenta de la población. La combinación de estos intereses emergía precisamente en un periodo de crecimiento de las importaciones. El consumo de mercancías extranjeras se articulaba con las prácticas cotidianas de las clases bajas, las cuales se mantuvieron intactas hasta mediados del siglo Xx (López, 2010, p. 95) en un espacio que aún no reconocía la diferencia entre lo rural y lo urbano (Laverde, 1889, p. 74).

Paradójicamente, como objeto de dicha transformación, fue concebida Bucaramanga, una ciudad bajo un incipiente proceso de urbanización. Sin

${ }^{44}$ Gaceta de Santander (fondo Publicaciones Oficiales, Decreto núm. 40, dirigido por el jefe departamental de García Rovira, 1876, núm. 1033, p. 93). Archivo Histórico Regional. Bucaramanga, Colombia.

${ }_{45}$ El Norte (fondo Periódicos, 1862, núm. 1, p. 3). Archivo Histórico Regional. Bucaramanga, Colombia. Véase además Informe (1871, p. 8). Archivo Histórico Regional. Bucaramanga, Colombia; Diario Oficial (1870, núm. 1790, p. 34). Archivo Histórico Regional. Bucaramanga, Colombia. 


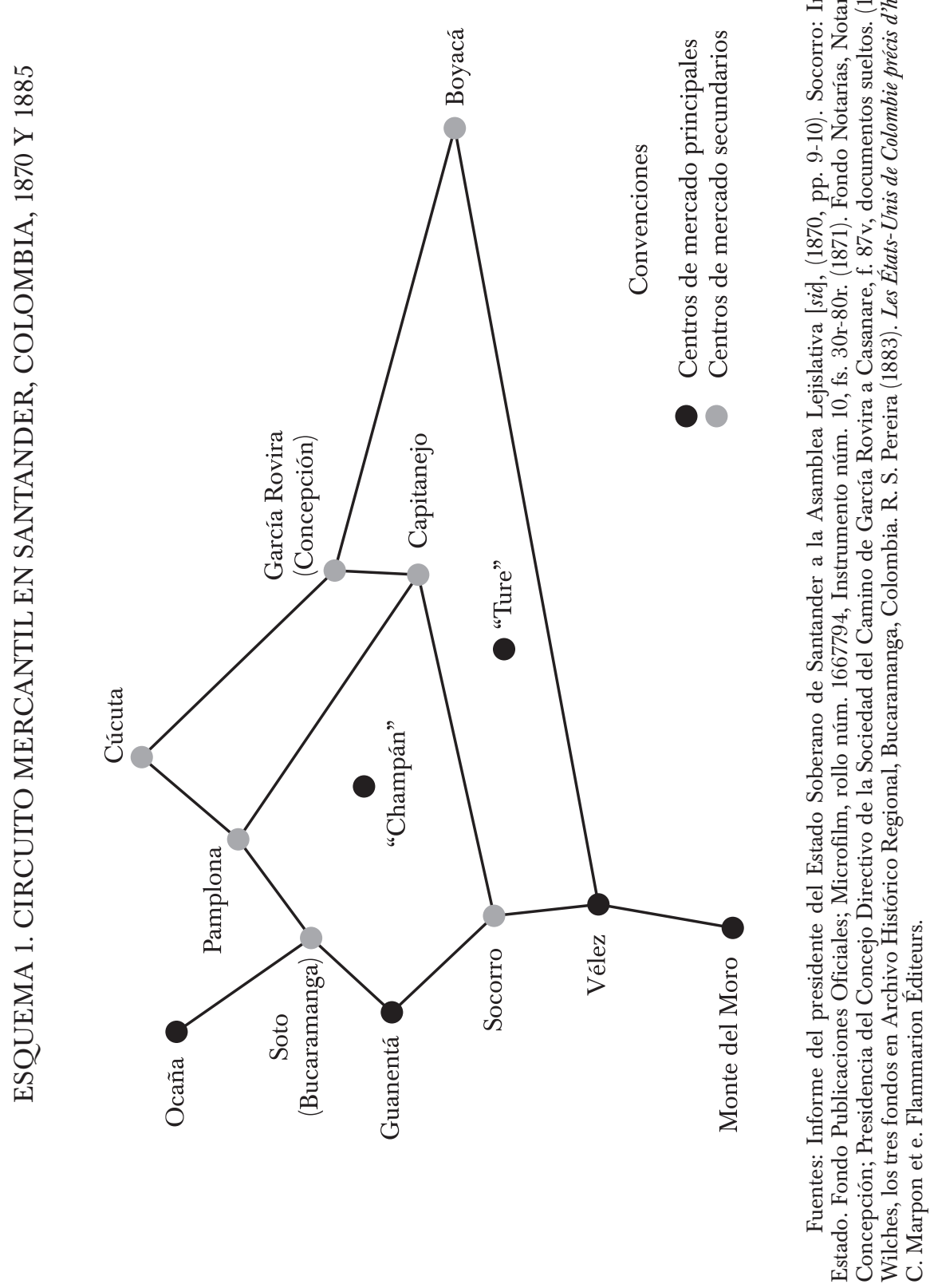


un proyecto concreto de acueducto y alcantarillado, con un rudimentario servicio de alumbrado público, con rústicas calles invadidas de caballos y mulas como tradicional servicio de transporte, y atestada en su famosa calle del comercio de numerosos almacenes de extranjeros dedicados a exportación de productos de la tierra y a la importación de mercancías finas (Rueda y Álvarez, 2012, p. 47). A su paso por Bucaramanga en 1886, Laverde Amaya se refirió a esta como una de las ciudades más comerciales del departamento de Santander, atiborrada de gente, con un gran grupo de comerciantes alemanes, pero escasa de agua y con construcciones poco notables (Laverde, 1889, pp. 58-59).

Los cambios ocurridos durante la segunda mitad del siglo XIX en la cultura material muestran que los efectos en los patrones de consumo al interior, en el contexto de las ciudades, no dependían de la clase social, teniendo en cuenta que en los negocios se estimaba poseer mercancías nacionales y extranjeras de igual manera. Así, el ritmo de la ciudad daba paso, por ejemplo, a la convivencia de lienzos finos con alpargatas de fique, donde colores y tejidos se mezclaban de formas variadas. Así, las costumbres en la alimentación y en el vestuario de uso cotidiano, como "la ruana, las alpargatas y el sombrero, que compartían escenario con el consumo de la chicha" (López, 2010, p. 13), fueron elementos muy importantes de los hábitos decimonónicos que con el tiempo se integraron al uso de las telas blandas de algodón y a la cerveza.

De acuerdo con Arjun Appadurai y Georg Simmel, esta perspectiva corresponde al concepto sobre la circulación de las mercancías en la vida social, en la que mercancías y personas poseen una vida social donde "el valor económico, $[$ sid nunca es una propiedad inherente de los objetos, sino un juicio acerca de ellos emitidos por los sujetos [...] por eso, el consumo es eminentemente social, correlativo, activo, en lugar de privado, atomizado y pasivo" (Appadurai, 1991, pp. 17, 48). En consecuencia, las dinámicas sociales y culturales del flujo de mercancías como los bienes de lujo eran considerados no tanto en oposición a las necesidades, sino como bienes cuyo uso esencial era "retórico y social", con signos incorporados (pp. 51-56).

Una clara señal de que los tiempos estaban cambiando se advirtió en los anuncios publicitarios que informaban sobre las novedades de los productos modernos (Henderson, 2006, p. 23), donde se fomentaron nuevos patrones de consumo y crearon necesidades, mismas que se observan en la alta demanda y la orientación de los gustos sobre dichas mercancías. Un pequeño esbozo, según Arnold Bauer (1999), del moderno capitalismo consumista de la década de 1860.

Un ejemplo de la transformación en el uso de las nuevas mercancías finas ocurre en 1887, en un anuncio publicitario de la Compañía Trinidad 
Parra de Orozco en el periódico El Impulso. En el anuncio se recomendaba a los consumidores la calidad del surtido de las mercancías inglesas, francesas y estadunidenses, tales como cortes de algodón, adornos para sala, driles, encajes, parches porosos allcocks, vestidos, ropa interior, flores artificiales, agua florida legítima de Murray \& Lanman, máquinas de coser, vinos tinto, blanco, vermouth, oporto y málaga imperial. No obstante, en dicho almacén, las mencionadas piezas coexistían con elementos típicos como las ruanas de paño y de merino, las gamuzas y las pieles de marrano. ${ }^{46}$ Con el cambio al siglo $\mathrm{xx}$, la publicidad enfatizaba no sólo la calidad, la novedad y el surtido de los productos, sino además promovía los "precios baratísimos". ${ }^{47}$

Los periódicos extranjeros trajeron consigo otro tipo de publicidad de diversos productos: moda, novelas, bordados, patrones para cortes de vestidos, piezas de música, figurines ${ }^{48}$ o catálogos en inglés y español con las nuevas tendencias en herramientas y coches. ${ }^{49}$ Con frecuencia se promovía el uso de productos extranjeros con el fin de incentivar el gusto por la moda e influir en la elección y compra de mercancías. Así, se introdujo la necesidad de usar artículos que reemplazaran aquellos baratos y de mala calidad producidos localmente. La publicidad indicaba el uso de cremas para mantener los dientes blancos, los perfumes para dar frescura a la boca, o el empleo de jabón y el perfume denominado "talismán de la belleza", que daba un sello aristocrático. ${ }^{50}$

Mercancías rústicas o nacionales y mercancías extranjeras se exhibían conjuntamente en gran parte de las tiendas, donde se compraba no sólo por el origen sino también por el bajo costo que representaban algunos productos fabricados localmente. En el inventario de bienes presentado por Vicente Restrepo como fiador de Agustín Cadena, para respaldar el préstamo de 400 pesos de ley procedentes del valor de unos efectos de tienda que les vendió Joaquín Acuña, se manifiesta sin preferencia alguna el tipo de objetos de uso diario destinados para dicho pago. Observándose que en los almacenes se vendían artículos muy a la usanza, como taburetes y

\footnotetext{
${ }^{46}$ El Impulso (fondo Periódicos, 1887, núm. 28, s. p.). Archivo Histórico Regional. Bucaramanga, Colombia.

${ }^{47}$ La novedad era el calzado americano, las muñecas, las alfombras de peluche, las cachuchas de seda, los porta-monedas y los relojes despertadores. Voz Liberal (fondo Periódicos, 1911, núm. 48, s. p.). Archivo Histórico Regional. Bucaramanga, Colombia. Colombia.

${ }^{48}$ Diario Oficial (1870, núm. 1819, p. 156). Archivo Histórico Regional, Bucaramanga,

${ }^{49}$ (Correspondencia enviada por Henderson \& Co. a los señores Paroline \& Acevedo, de Bucaramanga, 1893. Sección República, Aduanas, Correspondencia. 1825-1914, f. 66, carpeta 2, caja 3). Archivo General de la Nación. Bogotá, Colombia. Colombia.

${ }^{50}$ Diario Oficial (1870, núm. 1877, p. 390). Archivo Histórico Regional. Bucaramanga,
} 
mesas de madera usados, peroles de hierro esmaltados, bateas de madera, piedras de moler, platos esmaltados, bandejas de lata, ollas de barro y lazos. Bienes que imprimían su sello local en comparación con las lámparas, los vasos y las copas de vidrio, los pocillos esmaltados, o las bandejas y platos de China. ${ }^{51}$

En los niveles de mejores ingresos el uso excesivo de los objetos extranjeros sobresalía con mayor intensidad, destacándose las vajillas de plata, porcelana, vestidos franceses, libros de autores franceses, ingleses, italianos y españoles, así como el lujo en los artículos de tocador: colonias, jabones y aceites, cuartos con cortinas al estilo francés y adornados con flores artificiales. Era evidente el lujo y la apariencia demandados por las clases más notables de la ciudad para lograr demostrar al invitado extranjero su reputación, posición social y conocimiento de la etiqueta al mejor estilo inglés o español.

La moda europea destacaba en estas ciudades: "salones amueblados y decorados con lámparas, mesas, espejos, sillas, sofás, ventanas con vidrios, alfombras europeas, sillones y pianos" (Gosselman, 1981, p. 234). Muebles y ornamentos que sólo era posible llevarlos hasta aquellos lugares en la espalda de los peones o a lomo de mula. Se trataba de una comunicación dividida por cordilleras, es decir, mediante un dificultoso trayecto se separaba un ambiente austero y diferente. Se vestían como ingleses, elegantes, en casas decoradas al mejor estilo europeo, iluminadas con grandes lámparas o candelabros traídos de Inglaterra y con alfombras cuyo fin no sólo era decorar, sino además disimular la desigualdad de los pisos.

Por su parte, los grandes volúmenes de telas, ropa y artículos de lujo importados incidieron en la modificación de la moda popular, concediendo importancia tanto a las tiendas como a los almacenes de extranjeros. Sin olvidar que la fuerte y provocativa oferta comprometía el bolsillo de numerosos clientes que se endeudaron por encima de sus capacidades. Los individuos tomaban a crédito ropa y calzado para reproducir el lujo (Martínez, 1995, pp. 119-120), práctica que terminaba en demandas que llegaban hasta últimas instancias judiciales, como el caso de Francisco Velásquez, quien en 1877 presentó en una hoja útil la cuenta corriente de lo que le adeudaba la señora Amalia Hernández procedente de mercancías extranjeras, cuya cantidad llegaba a 246.5 pesos, en su mayoría telas para elaborar vestidos. ${ }^{52}$

\footnotetext{
${ }^{51}$ Sección Civil Ejecutivo (fondo Judicial de Bucaramanga, caja 116, fs. 1r-23r, 1894). Archivo Histórico Regional. Bucaramanga, Colombia.

${ }^{52}$ Sección Civil Ejecutivo (fondo Judicial de Bucaramanga, caja 105, fs. 1, 1877). Archivo Histórico Regional. Bucaramanga, Colombia.
} 
Según lo afirma Bauer (1999), a finales del siglo XIX el consumo a escala mundial aumentó y la introducción de artículos provenientes de los países industrializados se insertó en los modos y en los valores locales (p. 411). Colombia no estuvo ajena a este comercio, donde las mercancías se convirtieron en objetos de fácil acceso a los diversos grupos sociales, observándose por ejemplo en la introducción de materias primas como broches, botones, cintas de seda, piezas de encaje, hilos y telas de zaraza.

En el caso de Santander, los objetos manufacturados que ingresaban clandestinamente y decomisados en la aduana de San José de Cúcuta reflejan la trayectoria y la importancia que dichos objetos representaban al interior de la sociedad. Se hizo visible la preferencia por los vestidos de algodón, los relojes de mesa y de pared, la joyería de oro y plata, los zapatos, los jabones y el mobiliario para uso doméstico, como una forma de adoptar las modas urbanas, ya bastante interiorizadas en otros países; también se popularizó el uso de manteles, cuchillos, camisas y pañuelos de algodón, medias y sombreros (Laurent, 2008). A su vez, cambios importantes influyeron en la base material de la ropa, marcando una transición generalizada que pasó de la vestimenta rural al modelo urbano, emulando el modo de vestir de la clase alta y buscando distanciarse de sus costumbres originarias (Bauer, 1999, p. 489).

Convirtiéndose más en elementos de exhibición que de consumo (p. 440), los objetos manufacturados fuera del país obtuvieron una especie de valor moral, donde prevalecía no sólo la concepción entre lo moderno y lo antiguo, sino la búsqueda de identidad y familiaridad con el objeto, el cual terminaba pasando por todas las generaciones que integraban dichas familias. Por ejemplo, dentro de las mercancías heredadas a los hijos del fallecido Santafé Cadena, un reconocido comerciante de Bucaramanga, se destacan 16 alfombras, un fotomóvil, botellas de agua florida, planchas de vapor, piezas de seda, piezas de género Angola y Binuark, carretas de seda, lana, lienzo Massachusetts, satín, dril de lino, botones, botines y gorras. ${ }^{53}$

En relación con el contenido de las importaciones, los textiles de algodón y las materias primas se situaron en primer lugar, seguidos de los alimentos y bebidas, y las manufacturas de metal. En segundo lugar se situaron los objetos de lujo, los productos químicos, las manufacturas de cuero, las armas, municiones, combustibles, vidrio, materiales de construcción, madera, muebles y papel. Por último, las herramientas o instrumentos para la confección de ropa, como las máquinas de coser de pedal. Por su parte, $95 \%$ de las importaciones colombianas correspondía a bienes de

\footnotetext{
${ }^{53}$ Notaría Segunda de Bucaramanga (t. 4, 1892, f. 340r). Archivo Histórico Regional. Bucaramanga, Colombia.
} 
consumo (Ocampo, 1984), siendo predominante Gran Bretaña con 50\% de las importaciones de textiles y metales (Laurent, 2008).

En la lista de nuevas importaciones se incluían diversos artículos como ferretería, herramientas, máquinas de vapor, maquinaria y artículos alimenticios de lujo (latas de pescado, cerveza, vino francés o español). Cada uno de estos artículos tenía su propia historia, encerrando un extenso material de estudio que indicaría el trayecto que siguieron muchos productos que inicialmente fueron curiosidades exóticas y llegaron a ser objetos indispensables, símbolos de posición social y política (Bauer, 1999).

Provenientes de Francia llegaban tejidos de seda, lana y algodón, porcelanas, instrumentos de música y jabonería. Los bienes de consumo que ingresaron desde España exteriorizaron una marcada relación con los productos alimenticios como el aceite de oliva, ajos y cebollas, conservas alimenticias, sardinas, pescados, alpiste, anís, cominos, pastas para sopa, frutas secas, uvas y castañas. ${ }^{54}$ De Estados Unidos, galletas, harinas, productos químicos, medicinas, joyería y cobre manufacturado. ${ }^{55}$

Los productos pertenecientes al comercio minorista fueron comunes a los habitantes de zonas aledañas a Pamplona y Cúcuta, quienes acudían los días de mercado a dichas plazas para vender los productos de la tierra y proveerse de artículos extranjeros. En el caso de Pamplona, esta ciudad comenzó a cambiar sus viejos hábitos en la forma de vestir, pasando a usar ropas de colores y en la construcción de casas modernas con la invasión de las costumbres cucuteñas (Laverde, 1889).

A su vez, el creciente comercio con el territorio del Táchira estimuló a los "industriales en materias de tejido" ${ }^{56}$ del sur del Estado Soberano de Santander, del norte de Cundinamarca y Boyacá para conocer el prestigio que habían alcanzado las manufacturas en los mercados de Venezuela, ${ }^{57}$ especialmente en Táriba. Su feria anual efectuaba transacciones por cerca de medio millón de pesos, mediante operaciones comerciales donde el "batán socorrano" ${ }^{58}$ era el más estimado. La conducción semanal de valijas partía de Socorro para San Antonio de Táchira, pasando por Soatá,

${ }^{54}$ Diario Oficial (núms. 7613, 7614, 1888, pp. 1403-1404). Archivo Histórico Regional. Bogotá, Colombia, y Diario Oficial (núms. 7763-7764, 1889, p. 448). Archivo Histórico Regional. Bogotá, Colombia.

${ }_{55}$ Diario Oficial (núm. 2480, 1872, pp. 217-218); Diario Oficial (núm. 3268, 1874, p. 2118); Diario Oficial (núm. 7007, 1887, p. 391); Diario Oficial (núm. 9014, 1892, p. 1622), todos estos archivos en Archivo Histórico Regional. Bogotá, Colombia.

${ }^{56}$ Cancino (1883). La Integridad (fondo Periódicos, núm. 23, s. p.). Archivo Histórico Regional. Bucaramanga, Colombia.

${ }^{57}$ Sección República (fondo Gobernaciones Socorro, rollo núm. 442, f. 287). Archivo Histórico Regional. Bucaramanga, Colombia.

${ }^{58}$ La Integridad (fondo Periódicos, núm. 23, 1883, s. p.). Archivo Histórico Regional. Bucaramanga, Colombia. 
Málaga, Concepción, Pamplona, San José y Rosario de Cúcuta, llegando a conducir hasta seis arrobas de peso.

Cada 15 de agosto llegaban a la tradicional feria mantas ordinarias, finas, mantas pinta-pinta finas y ordinarias, mantas de enjalmas socorranas y de Curití, pinta garnica y fina, hamacas, colchas comunes y manteles, toallas o paños de mano, alpargatas superiores finas para hombre y mujer, gamuzas, badanas, ${ }^{59}$ baquetas, ${ }^{60}$ correajes de toda clase, sombreros raspones o embarillados, sombreros superiores imitación suaza ${ }^{61}$ y suazas de copa redonda, chamauetas ${ }^{62}$ de hilo, chamauetas de lana y cigarros. ${ }^{63} \mathrm{~A}$ su vez, dentro de los artículos procedentes del interior del país que llegaban a dicha feria se encontraban los paños burdos o cortes de lana para calzón con calidad en su manufactura, "por su abrigo y duración incuestionable" y cuyas fábricas se localizaban en Lenguazaque, Ubaté y algunos pueblos de Boyacá, poco conocidos en el territorio del Táchira.$^{64}$

Los puertos también se convirtieron en lugares destinados a la compraventa de mercaderías. En 1870, en el puerto de Los Cachos, se vendían productos a menor precio que en las plazas ya que ingresaban ilícitamente. Por lo general estas mercaderías eran bajadas de embarcaciones menores en las playas distantes de los puertos, donde los habitantes los sacaban por los caminos de la montaña hasta ponerlos lejos de la vigilancia de los resguardos (Laurent, 2008, p. 380). La cantidad y variedad de mercancías extranjeras introducidas por contrabando hacían referencia en su mayoría a artículos finos. ${ }^{65}$ En las mercancías ingresadas fraudulentamente y rematadas por la Aduana de Cúcuta, se encontraron pañuelos de seda, botines para mujer de género y cuero charolado, pendientes o zarcillos de vidrio, peines, espejos, relojes, cruces de cobre y muñecas de madera, hasta herramientas de todo tipo, maquinaria y hierro. ${ }^{66}$

${ }^{59}$ Piel curtida y fina de carnero u oveja. Real Academia de la Lengua (RAE).

${ }^{60}$ Vara delgada de hierro o madera, con un casquillo de cuerno o metal, que servía para atacar las armas de fuego y hoy para desembarazar su ánima, o varilla seca de membrillo u otro árbol, que usan los picadores para el manejo de los caballos. RAE.

${ }^{61}$ Jipijapa o palma de iraca. RAE.

${ }^{62}$ Ruanas.

${ }^{63}$ Los cigarros locales, de diferentes especies como: corriente, flor fina, panetelas (de perilla), panetelas (americanos recortados), cañones, recortados, y cocheteros también se comercializaron particularmente en plazas como Cúcuta, Pamplona y Maracaibo. Véase Carta de Clemente Blanco a Solón Wilches, Pamplona, 1888. Fondo Wilches (caja núm. 10, s. f.). Carta de José Ferrare [sic] a Solón Wilches, Málaga, 1889. Fondo Wilches (caja núm. 10, s. f.). Carta de Clemente Blanco a Solón Wilches. Pamplona, 1889. Fondo Wilches (caja núm. 10, s. f.).

${ }^{64}$ La Integridad (fondo Periódicos, 1883, núm. 23, s. p.). Archivo Histórico Regional, Bucaramanga, Colombia.

${ }_{66}^{6}$ Diario Oficial (1873, núm. 2969, p. 922). Archivo Histórico Regional. Bucaramanga, Colombia. 
A mediados del siglo XIX y después del terremoto de Cúcuta en 1875, la población fue tomando semejanzas y costumbres del vecino país Venezuela y de Europa. En 1851 el colombiano Manuel Ancízar observó durante su viaje a las provincias del norte de la Nueva Granada el alto consumo de ropa extranjera entre jornaleros, proletarios, indios y ricos, quienes tenían un consumo anual de 3154000 pesos (Ancízar, 1853).

Sobre la interpretación de los bienes materiales se puede mencionar a Arnold Bauer, quien señala que durante la primera mitad del siglo XIX las líneas divisorias entre las clases sociales rápidamente se traslaparon para difuminarse, surgiendo así poblaciones mestizas. Tanto los estratos superiores como los inferiores buscaron, mediante lo que consumían y la manera como lo hacían, la forma de orientarse en un laberinto de significado cultural; en esa medida, destaca la ropa y sus diferente usos diarios, en lo público y lo privado (Bauer, 1999). Por tanto, desde la colonia, el surgimiento de las importaciones europeas de bajo precio, muy reconocidas teniendo en cuenta los cambios en la moda, eran de extrema importancia para la población en general. Las personas utilizaban imitaciones, las mujeres intentaban vestirse como españolas, y a los mestizos, indios, mulatos y negros les gustaba la ostentación (Bauer, 1999, pp. 455-456). Expresiones que se afianzaron aún más a finales del siglo con el creciente comercio de importación.

En estos términos, los pobladores de San José de Cúcuta imitaban costumbres propias de las clases altas

como el vestido y las habitaciones [...] al presente es rara la mujer del pueblo que no tiene a su hija calzada con brecas, como allá dicen, con camisones y saco largo (paletó) de zaraza. El ancho pañuelo de color vistoso, cruzado sobre el pecho, no falta a ninguna persona cuyo criterio conceptúa preciso y atinado, me decía que este vestido las ha levantado [...] con lo que quería decir, que para el pueblo suelen traer la moda y el lujo relativo consecuencias morales significativas (Urdaneta, 1986, pp. 256-257).

La costumbre de comercializar y fabricar artículos de consumo diario desapareció o simplemente se redujo por el ingreso de mercaderías extranjeras (Laverde, 1889, p. 30).

\section{CONCLUSIÓN}

Durante la segunda mitad del siglo XIX y comienzos del XX se observó un incremento en la importación y consumo de mercancías finas. Sin importar la calidad, la capacidad, el manejo administrativo, los riesgos por 
el contrabando y la infraestructura de los puertos regionales y locales, la formación de nuevas casas comerciales, tanto de extranjeros como de nacionales, promovió cambios en el consumo de los pobladores al introducir mercancías novedosas, foráneas y quizá lucrativas.

El circuito comercial de importación en Santander se caracterizó por combinar dos elementos importantes. En primer lugar, la conformación de casas comerciales donde se destaca, por un lado, la incursión de comerciantes y familias extranjeras, principalmente alemanas; por otro, la conformación de sociedades familiares principalmente oriundas de la región, que al final terminaron incorporando a su grupo a los comerciantes extranjeros bajo el respaldo de los matrimonios concertados. Las estrategias utilizadas dependían no sólo de los casamientos, también influyeron las asociaciones financieras, la fusión de capitales y los favores políticos. Estas conexiones llevaron a que en Santander se concentrara una parte importante de comerciantes que terminaron coincidiendo en las prácticas monopólicas y en la incorporación de funciones políticas en el movimiento comercial. En segundo lugar, el crecimiento de las importaciones de artículos extranjeros, vinculado con dicha red comercial y con las compañías establecidas en Alemania, Inglaterra, Estados Unidos, España y Francia, dependió a su vez de los medios internos de comunicación tanto fluvial como terrestre para conectarlos. Aun cuando el envío de mercancías desde el puerto de Barraquilla (por el río Magdalena) hacia los puertos de pequeña escala en Santander aumentó notablemente a finales del siglo XIX; el puerto de Maracaibo fue el principal circuito comercial utilizado para abastecer las casas comerciales de Bucaramanga y Cúcuta, las ferias anuales de Santander y las plazas comerciales del suroeste venezolano, en la frontera con Colombia.

Es evidente que la orientación sobre las mercancías extranjeras no sólo fue incentivada por las instituciones en la búsqueda de mejorarías en las condiciones materiales, cambios en los hábitos, costumbres o antiguos modos de vida con el fin de incursionar en el capitalismo. También el flujo de mercancías finas invadió los espacios de pequeñas y grandes ciudades, irrumpió en los reconocidos almacenes de personajes notables, y al mismo tiempo las pulperías, las tiendas y locales de personajes desconocidos y de la población en general. Dichas mercancías provocaron conflictos, deudas, pero también asociaciones, gremios y hasta asesinatos. Desconocer el uso de estos bienes significaría también negar el contrabando, la compraventa al menudeo y la incorporación de lo foráneo en la vida material de la sociedad, así como la travesía entre grandes y pequeños puertos, ríos, caminos de herradura y geografías adversas. 


\section{LISTA DE REFERENCIAS}

AncízAr, M. (1853). Peregrinación de Alpha: por las provincias del norte de la Nueva Granada en 1850 i 51. Biblioteca Luis Ángel Arango del Banco de la República, Colombia. Recuperado de http//www.banrepcultural.org

APPADURAI, A. (1991). Introducción: las mercancías y la política del valor. En A. APPADURAI (ed.), La vida social de las cosas (pp. 17-87). México: Grijalbo/Consejo Nacional para la Cultura y las Artes.

Avellaneda, M. (1999). Los comerciantes de la Bucaramanga de finales del siglo XIX (Trabajo de pregrado en Historia). Universidad Industrial de Santander, Bucaramanga.

Bauer, A. J. (1999). La cultura material. En M. Carmagnani, A. Hernández y R. Romano (coords.), Para una historia de América: Vol. 1. Las estructuras (pp. 404-497). México: El Colegio de México/Fideicomiso Historia de las Américas.

Braudel, F. (1993). La identidad de Francia. Los hombres y las cosas (t. III). Barcelona: Gedisa.

CARReÑo, C. I. (2007). Construir caminos para conducir cargas y especular con tierras: los caminos de Lebrija y Sogamoso en el Departamento de Soto, 1865-1885 (Trabajo de pregrado en Historia). Universidad Industrial de Santander, Bucaramanga.

Correa, J. S. (2012). El ferrocarril de Bolívar y la consolidación del puerto de Barranquilla (1865-1941). Revista de Economía Institucional, 14(26), 241-266.

DuQue, M. F. (enero-junio, 2005). Comerciantes y empresarios de Bucaramanga (1857-1885): una aproximación desde el neoinstitucionalismo. Historia Crítica, 29, 149-184.

Espínola, E. (2006). Christern \& Co: 1876-1899. Formación de una firma alemana en Maracaibo. En Viejas y nuevas alianzas entre América Latina y España: XII Encuentro de Latinoamericanistas Españoles (pp. 1-17). Santander: Consejo Español de Estudios Iberoamenricanos.

García, J. J. (1982). Crónicas de Bucaramanga. Bogotá: Banco de la República.

Gosselman, C. A. (1981). Viaje por Colombia, 1825-1826. Bogotá: Banco de la República.

Guerrero, A. y Avellaneda, M. (2002). Memoria empresarial santandereana. En P.

A. Vivas (comp.), Memoria empresarial santandereana. Artes gráficas. Bucaramanga:

(Sic) Editorial/Universidad Industrial de Santander.

GutiÉRrez, F. (2012). Las comunicaciones en la transición del siglo XIX al XX en el sistema territorial colombiano. Medellín: Universidad Nacional de Colombia.

Henderson, J. D. (2006). La modernización en Colombia: los años de Laureano Gómez 1889-1965. Medellín: Universidad de Antioquia.

Laurent, M. (2008). Contrabando en el siglo XIX. Prácticas y discursos de resistencia y reproducción. Bogotá: Universidad de los Andes.

LAVERDE, I. (1889). Un viaje a Venezuela. Bogotá: Imprenta de la Nación.

López, M. P. (2010). Salarios, vida cotidiana y condiciones de vida en Bogotá durante la primera mitad del siglo Xx. Ponencia presentada en el II Congreso Latinoamericano de Historia Económica. Ciudad de México. 
Martínez, A. (1995). La prisión del vestido: aspectos sociales del traje en Colombia. Bogotá: Planeta.

OCAMPO, J. A. (1984). Colombia y la economía mundial. 1830-1910. Bogotá: Siglo XXI.

Pabón, Y. F. (2011). Historia del ferrocarril de Cúcuta. Desde el camino a San Buenaventura hasta la compañía del ferrocarril, 1865-1959 (Tesis de maestría). Universidad Industrial de Santander, Bucaramanga.

RAmírez, A. (2009). Los efectos de la extracción y exportación de la corteza de quina en el departamento de Soto, Estado Soberano de Santander, 1876-1884 (Trabajo de pregrado en Historia). Universidad Industrial de Santander, Bucaramanga.

Ramírez, M. T. y PACHÓn, Á. (2006). La infraestructura del transporte en Colombia durante el siglo XX: una descripción desde el punto de vista económico. Bogotá: Fondo de Cultura Económica.

SAFFORD, F. (2010). El problema de los transportes en Colombia en el siglo XIX. En A. Meisel-Roca, M. T. Ramírez (eds.), Economía colombiana del siglo XIX (pp. 523573). Bogotá: Fondo de Cultura Económica/Banco de la República de Colombia.

Rueda, N. y Álvarez, J. (2012). Historia urbana de Bucaramanga, 1900-1930. Bucaramanga: Universidad Industrial de Santander.

Urdaneta, A. (abril-junio, 1986). San José de Cúcuta en el comercio marabino del siglo XIX. Tierra Firme, 14(4), 177-192. 